\title{
Generation in Plasma of a Fast-acting Inhibitor of Plasminogen Activator in Response to Endotoxin Stimulation
}

\author{
M. Colucci, J. A. Paramo, and D. Collen \\ Center for Thrombosis and Vascular Research, University of Leuven, Leuven, Belgium
}

\begin{abstract}
Endotoxin producing bacteria cause disseminated intravascular coagulation (DIC); however, the mechanism of endotoxin action in man is still unclear. Impairment of the fibrinolytic system has been suggested as a contributing mechanism.

A single injection of Escherichia coli lipopolysaccharide in rabbits resulted in a marked and prolonged increase of the levels of a fast-acting inhibitor of plasminogen activator (PAinhibitor) in plasma (from $3.9 \pm 0.7$ to $41 \pm 13.2 \mathrm{U} / \mathrm{ml}$ after 3 h). Gel filtration studies indicated that inhibition of human tissue-type plasminogen activator (t-PA) by rabbit plasma is accompanied by a change in the elution profile of the activator compatible with the formation of an enzyme-inhibitor complex with an apparent molecular weight of 100,000 . Injection of human t-PA (1,500 IU/kg body wt) in endotoxin treated animals resulted in very fast inhibition of $t-P A$ and formation of a similar complex.

The half-life of circulating PA-inhibitor activity in rabbits was about $7 \mathrm{~min}$ as estimated by donor receiver plasma transfusion experiments.

Stimulation of cultured human endothelial cells with endotoxin resulted in enhanced rate of accumulation of PAinhibitor activity in the culture medium (two- to sevenfold increase). In five patients with septicemia, markedly increased levels of PA-inhibitor $(14.3 \pm 15.5 \mathrm{U} / \mathrm{ml})$ as compared with control subjects $(1.3 \pm 0.7 \mathrm{U} / \mathrm{ml})$ were observed in plasma.

A very strong correlation $(r=0.98)$ was found between inhibition of t-PA and of urokinase in all conditions, suggesting that this fast-acting inhibitor reacts with both plasminogen activators.

These data suggest that the appearance of this fast-acting PA-inhibitor is very sensitive to endotoxin stimulation. The marked increase in the level of PA-inhibitor in blood may contribute to the pathogenesis of DIC in septicemia.
\end{abstract}

\section{Introduction}

Bacterial infections may cause disseminated intravascular coagulation (DIC) ${ }^{1}$ and fibrin deposition in the microcirculation

Dr. Paramo was the recipient of a fellowship from Ministerio de Educacion y Ciencia, Spain.

During these studies, Dr. Colucci is on leave from Istituto di Ricerche Farmacologiche "Mario Negri," Milano, Italy; and Dr. Paramo is on leave from Clinica Universitaria de Navarra, Pamplona, Spain.

Address correspondence to Dr. Collen, Center for Thrombosis and Vascular Research, Campus Gasthuisberg, Herestraat 49, 3000 Leuven, Belgium.

Received for publication 8 August 1984 and in revised form 13 November 1984.

J. Clin. Invest.

(C) The American Society for Clinical Investigation, Inc.

0021-9738/85/03/818/07 \$1.00

Volume 75, March 1985, 818-824
(1, 2). Endotoxin, a cell wall constituent of gram-negative bacteria, has been shown to be the main trigger of these phenomena (3). Its mechanism of action, however, is not completely clarified.

Endotoxin-induced DIC is a multifactorial process that involves both cellular and humoral pathways (3). Endothelial cell damage with exposure of the subendothelial structures has been proposed as one of the main pathogenetic mechanisms $(3,4)$. In addition, endotoxin-stimulated endothelial cells may trigger blood coagulation by producing procoagulant (thromboplastin-like) activity (5).

Deficient fibrinolysis may contribute to the precipitation of fibrin within blood vessels (6). Indeed, the fibrinolytic system plays a role not only in the removal of formed fibrin but also in the prevention of fibrin deposition (7).

Endothelial cells produce and release plasminogen activator(s) and inhibitor(s) of plasminogen activation (8-12). Recent reports have shown that circulating blood contains a fastacting inhibitor of tissue-type plasminogen activator (t-PA) and urokinase (UK) (PA-inhibitor) (13-15) that may be identical to the inhibitor produced by endothelial cells.

This study shows that $(a)$ injection of very small amounts of endotoxin in rabbits induces a marked increase of PAinhibitor activity in circulating blood, $(b)$ endotoxin enhances the accumulation of PA-inhibitor activity in the culture medium of human endothelial cells, and $(c)$ patients with septicemia have markedly increased levels of PA-inhibitor in blood.

It is concluded that the appearance of PA-inhibitor activity after endotoxin stimulation may play a significant role in the pathogenesis of DIC associated with septicemia. Endotoxin stimulation, in experimental animals, may provide a useful model for the investigation of the biological role of PAinhibitor.

\section{Methods}

Materials. Human melanoma cell t-PA, human plasminogen, and human fibrinogen were purified by published methods (16-18). Urokinase (UK) (Winkinase) was a gift from Dr. G. Murano, Bureau of Biologics, Food and Drug Administration, Bethesda, MD. Fibrinogen was digested with $\mathrm{CNBr}$ as previously described (19). Fibrinogen was labeled with ${ }^{125}$ I using the Iodo-Gen procedure (20). t-PA was immobilized by coupling to $\mathrm{CNBr}$-activated Sepharose $4 \mathrm{~B}(0.2 \mathrm{mg}$ protein/ g gel). Escherichia coli 0111:B4 lipopolysaccharide (LPS) W was purchased from Difco Laboratories, Inc., Detroit, MI. The synthetic substrate D-Val-Leu-Lys-pNA (S-2251) was purchased from Kabi Diagnostica, Stockholm, Sweden. Arg-vasopressin (AVP) was purchased from Sigma Chemical Co., St. Louis, MO. D-Ile-Pro-Arg- $\mathrm{CH}_{2} \mathrm{Cl}$, a synthetic inhibitor of t-PA, is characterized elsewhere (21).

1. Abbreviations used in this paper: AVP, Arg-vasopressin; DIC, disseminated intravascular coagulation; HEC, human endothelial cells; LPS, lipopolysaccharide; PA-inhibitor, designation used for a fastacting inhibitor of tissue-type plasminogen activator and urokinase; t-PA, tissue-type plasminogen activator; UK, urokinase. 
In vivo experiments. New Zealand rabbits, weighing $1.8-2.1 \mathrm{~kg}$, were anesthetized by intramuscular injection of $0.4 \mathrm{ml} / \mathrm{kg}$ body wt of Hypnorm (Duphar, Amsterdam, The Netherlands) containing $10 \mathrm{mg} /$ $\mathrm{ml}$ fluanisone and $0.2 \mathrm{mg} / \mathrm{ml}$ fentanil. Additional Hypnorm $(0.3 \mathrm{ml}$ every $2 \mathrm{~h}$ ) was administered to maintain anesthesia. LPS injections were given via a marginal ear vein. Blood samples $(2 \mathrm{ml})$ were taken through a catheter inserted into a femoral vein and anticoagulated with $4 \%$ trisodium citrate ( 9 vol of blood plus 1 vol of anticoagulant) or, when specified, with citrate plus D-Ile-Pro-Arg- $\mathrm{CH}_{2} \mathrm{Cl}\left(2 \times 10^{-4} \mathrm{M}\right.$ final concentration). Samples were immediately chilled in melting ice; plasma was isolated by short centrifugation $(2 \mathrm{~min}$ at $12,000 \mathrm{~g}$ ) within 10 min of sampling and kept on ice until tested.

In vitro studies. Human endothelial cells (HEC) were prepared from umbilical cord veins as described (10). The endothelial cells were aliquoted in tissue culture plates with flat-bottomed wells of $16 \mathrm{~mm}$ diam (Becton-Dickinson \& Co., Oxnard, CA). After 7-8 d, primary confluent cultures containing only the typical cobblestone patterns of endothelial cells were used. The average number of cells was $2 \times 10^{5}$ per well. Each series of experiments was performed on cultures derived from the same umbilical cord vein. The culture medium was removed, the cell monolayers were washed three times with serum-free medium, and then $0.8 \mathrm{ml}$ of fresh culture medium containing $5 \%$ of heatinactivated human serum $\left(30 \mathrm{~min}\right.$ at $\left.56^{\circ} \mathrm{C}\right)$ was added. $E$. coli LPS or sterile saline were added to the cells and the cultures were incubated at $37^{\circ} \mathrm{C}$. Aliquots of conditioned culture medium were taken at the indicated time intervals to assay PA-inhibitor activity. The cell associated PA-inhibitor activity was evaluated as follows. After 12-14 h incubation with endotoxin or saline, the culture medium was removed and the cell monolayers were washed three times with phosphate-buffered saline (PBS). Cells were then extracted with $0.5 \%$ Triton X-100 $(0.2$ $\mathrm{ml}$ ) for $30 \mathrm{~min}$ at room temperature. Alternatively, the endothelial cells were disrupted by freezing and thawing (5) and were centrifuged $15 \mathrm{~min}$ at $40,000 \mathrm{~g}$. The supernatant (soluble fraction) was collected and the pellet (membrane fraction) was washed twice with PBS and then extracted with Triton X-100.

Blood platelets and leukocytes were isolated as described elsewhere $(22,23)$. Final suspensions were in PBS and contained $5 \times 10^{5}$ platelets/ $\mu \mathrm{l}$ and $10^{4}$ leucocytes $/ \mu \mathrm{l}$, respectively. Cells were extracted with Triton $\mathrm{X}-100$ as outlined above.

Assay of plasminogen activator activity. Fibrinolytic activity of the euglobulin fraction of rabbit plasma was evaluated by measuring the release of ${ }^{125} \mathrm{I}$ from radiolabeled fibrin films $(24,25) .100 \mu \mathrm{l}$ of euglobulins was added to the wells and the plates were incubated at $37^{\circ} \mathrm{C}$. 10- $\mu$ l samples were removed at fixed time intervals for the measurement of ${ }^{125} \mathrm{I}$-fibrin split products. Plasminogen activator activity was expressed in international units (16) by reference to a standard curve made with purified human t-PA in plasminogen-containing $(0.25-\mu \mathrm{M})$ wells.

t-PA activity in plasma after injection of human t-PA was measured with the fibrin plate method (26) as reported (16), and with a synthetic substrate assay (27). In the latter case, citrated blood samples $(0.4 \mathrm{ml})$ were immediately acidified with $1 \mathrm{M} \mathrm{Na}$-acetate, $\mathrm{pH} 3.9(0.2 \mathrm{ml})$, and centrifuged. The resulting plasma was incubated for an additional 10 min at room temperature and then diluted $1 / 50$ in $0.02 \mathrm{M}$ Tris $\cdot \mathrm{HCl}$, $0.1 \mathrm{M} \mathrm{NaCl}, 0.01 \%$ Triton X-100, $\mathrm{pH}$ 8.8. The samples were kept on ice until tested for t-PA activity. $100 \mu \mathrm{l}$ of the test solution and $100 \mu \mathrm{l}$ of a mixture containing $0.25 \mu \mathrm{M}$ human plasminogen, $0.6 \mathrm{mM}$ $\mathrm{S}-2251$, and $0.09 \mathrm{~g} / \mathrm{l} \mathrm{CNBr}$ fibrinogen digest were added in a microtiter plate. The plate was incubated at $37^{\circ} \mathrm{C}$ and the change in absorbance at $405 \mathrm{~nm}$ was measured with a titertek multiskan spectrophotometer (Flow Laboratories, Inc., McLean, VA).

t-PA related antigen was measured using a two-site immunoradiometric assay as previously described (28).

Assay of PA-inhibitor activity. Samples were diluted $1 / 4$ or more in $0.02 \mathrm{M}$ Tris $\cdot \mathrm{HCl}, 0.1 \mathrm{M} \mathrm{NaCl}, 0.01 \%$ Triton X-100, pH 8.8 (Tris buffer), and incubated for $1 \mathrm{~min}$ at $37^{\circ} \mathrm{C}$ in the presence of t-PA or UK $(2 \mathrm{IU} / \mathrm{ml}$ final concentration). The samples $(100 \mu \mathrm{l})$ were then acidified with $100 \mu \mathrm{l}$ of $0.16 \mathrm{M} \mathrm{HCl}$ and incubated $10 \mathrm{~min}$ at room temperature. This procedure resulted in complete neutralization of the plasmin inhibitor activity in plasma. The $\mathrm{pH}$ was then adjusted by the addition of $100 \mu \mathrm{l}$ of $0.16 \mathrm{M} \mathrm{NaOH}$ and $700 \mu \mathrm{l}$ of Tris buffer. The residual plasminogen activator activity was measured by the synthetic substrate assay described above. Inhibitor activity was expressed in units of plasminogen activator inhibited per milliliter.

Fibrin polymerization time, activated partial thromboplastin time, and platelet count were performed by standard laboratory assays.

Gel filtration of plasma samples $(0.5 \mathrm{ml})$ was performed on an Ultrogel AcA 44 column $(30 \times 1.6 \mathrm{~cm})$ equilibrated with $0.02 \mathrm{M}$ Tris $\cdot \mathrm{HCl}, 0.3 \mathrm{M} \mathrm{NaCl}, 0.01 \mathrm{M}$ trisodium citrate, and $0.02 \%$ Tween $80, \mathrm{pH} \mathrm{7.4}$. The flow rate was $10 \mathrm{ml} / \mathrm{h}$ and fractions of $1 \mathrm{ml}$ were collected. Relative molecular weight markers were: human IgGs, $M_{\mathrm{r}}$ $=150,000$; phosphorylase $\mathrm{b}, M_{\mathrm{r}}=98,000$; and human albumin, $M_{\mathrm{r}}$ $=66,000$.

Adsorption of PA-inhibitor activity from samples was carried out as follows. t-PA-Sepharose was added to the sample $(100 \mathrm{mg} \mathrm{gel} / \mathrm{ml})$ and the mixture was incubated at $37^{\circ} \mathrm{C}$ for 30 min under continuous mixing. The gel was sedimented by centrifugation $(2 \mathrm{~min}$ at $12,000 \mathrm{~g}$ ) and the top fraction of the supernatant was collected.

Patients. The PA-inhibitor activity of plasma was studied in five patients with septicemia; four males and one female, aged 22-76 yr (mean 57). Bacteriological studies identified E. coli, Pseudomona aeruginosa, and Streptococcus viridans. A control group consisted of 50 healthy subjects, 31 males and 19 females, aged 26-61 yr (mean 39).

\section{Results}

In vivo studies in rabbits. The PA-inhibitor activity in the plasma of rabbits after injection of $E$. coli LPS is illustrated in Fig. $1 A$. After $3 \mathrm{~h}$ of endotoxin administration, the inhibitor levels rose from $3.9 \pm 0.7 \mathrm{U} / \mathrm{ml}$ to $41 \pm 13.2 \mathrm{U} / \mathrm{ml}$. This level was maintained for an additional $5 \mathrm{~h}$ and had returned to the preinjection value after $24 \mathrm{~h}$. Adsorption of plasma obtained from endotoxin treated animals with t-PA-Sepharose completely removed the PA-inhibitor activity (not shown).

With this endotoxin preparation, overt signs of intravascular coagulation, such as drop in platelet count, reduction of fibrinogen levels, and prolongation of the activated partial thromboplastin time, were visible only when a dose of 200 $\mu \mathrm{g} / \mathrm{kg}$ body wt was given to the animals, whereas a PAinhibitor response (more than fivefold increase) was clearly observed with a dose as low as $10 \mathrm{ng} / \mathrm{kg}$ (Fig. $1 \mathrm{~B}$ ).

PA-inhibitor activity was barely detectable in extracts of washed blood platelets and leukocytes $\left(0.14 \pm 0.2 \mathrm{U} / 10^{8}\right.$ cells and $0.5 \pm 0.6 \mathrm{U} / 10^{7}$ cells, respectively). The PA-inhibitor activity of platelets or leukocytes isolated from blood samples collected 3 and $5 \mathrm{~h}$ after injection of LPS was not different from that of cells obtained from animals injected with saline (not shown). In addition, no increase in inhibitor activity was observed in plasma samples prepared from whole rabbit blood incubated for different time intervals (up to $6 \mathrm{~h}$ ) with endotoxin $(10 \mu \mathrm{g} /$ $\mathrm{ml}$ blood) in vitro.

The following experiments were carried out to establish whether the PA-inhibitor induced by endotoxin neutralized the endogenous plasminogen activator released in vivo. Animals were first injected with endotoxin $(10 \mu \mathrm{g} / \mathrm{kg})$ or saline, and 3 $\mathrm{h}$ later, with AVP $(10 \mu \mathrm{g} / \mathrm{kg})$. Blood samples were taken before and 2, 5, 10, and 20 min after injection of AVP and immediately processed for plasminogen activator assay. The results are shown in Fig. 2. In control animals, AVP induced a clear increase of the euglobulin fibrinolytic activity. Preinjection of endotoxin completely abolished the AVP-induced fibrinolytic response. 


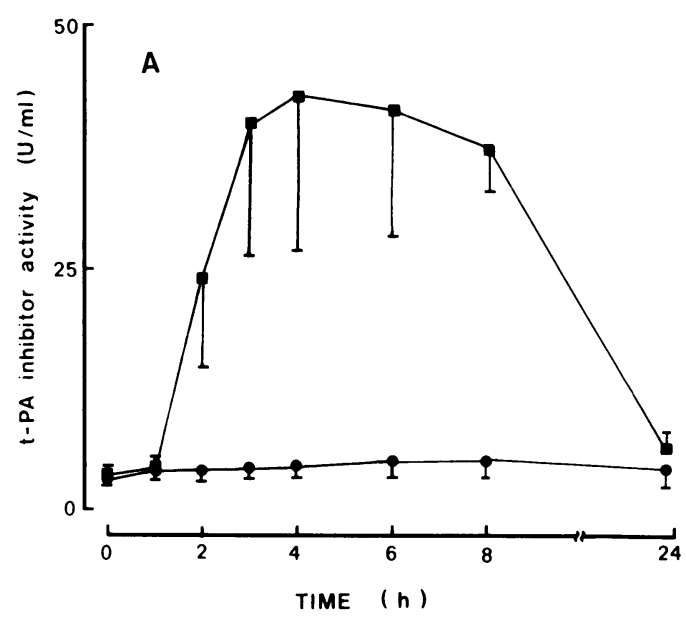

To further document that inhibition of plasminogen activator occurred in vivo, endotoxin treated animals were injected with 1,500 IU of human t-PA/kg body wt and blood samples were taken at intervals on D-Ile-Pro-Arg- $\mathrm{CH}_{2} \mathrm{Cl}\left(2 \times 10^{-4} \mathrm{M}\right.$ final concentration). Gel filtration analysis of plasma samples obtained from untreated animals $30 \mathrm{~s}$ after injection of activator showed that most of the t-PA eluted in the albumin region (Fig. $3 \mathrm{~A}$ ). On the contrary, in plasma from animals with high circulating levels of PA-inhibitor, virtually all of the t-PA related antigen eluted with an apparent molecular weight of 100,000 (Fig. 3 B). A similar change in the elution profile was observed when human t-PA was added to PA-inhibitor-rich blood in vitro followed by addition of D-Ile-Pro-Arg- $\mathrm{CH}_{2} \mathrm{Cl}$ after 2 min of incubation, but not when the synthetic inhibitor was added before t-PA. This indicates that complex formation between t-PA and PA-inhibitor in rabbit blood, after injection of human t-PA, does not occur in vitro after collection of the sample.

The disappearance of fibrinolytic activity in control rabbits injected with human t-PA (1,500 IU/ $/ \mathrm{kg}$ body wt) was consistent with a half-life of $\sim 2 \mathrm{~min}$. On the contrary, in endotoxin treated animals, no activity $(<0.1 \mathrm{U} / \mathrm{ml})$ was detected $30 \mathrm{~s}$ after t-PA injection, suggesting a half-life of a few seconds (not shown).

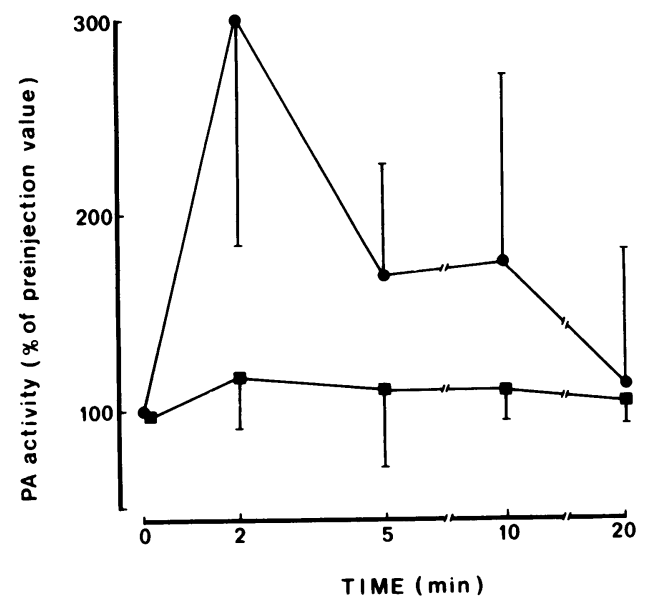

Figure 2. Fibrinolytic response to AVP $(10 \mu \mathrm{g} / \mathrm{kg})$ in rabbits treated

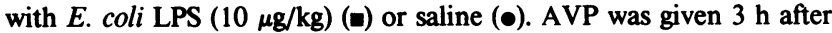
injection of LPS or saline. Data are the mean \pm SD of three experiments.

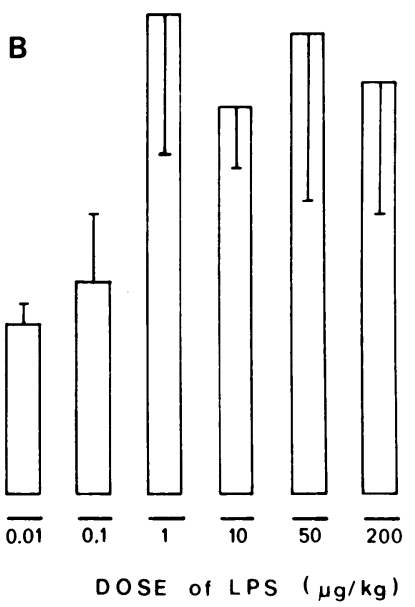

Figure 1. (A) PA-inhibitor response in rabbits injected with $E$. coli LPS $(10 \mu \mathrm{g} / \mathrm{kg}$ or $50 \mu \mathrm{g} / \mathrm{kg})(\square)$ or saline (๑). Results represent the mean \pm SD of five experiments. $(B)$ PA-inhibitor activity in rabbit plasma $4 \mathrm{~h}$ after injection of different doses of $E$. coli LPS. Results are the mean and SD of three experiments or the mean and range of two experiments.
Injection of $1,000 \mathrm{IU}$ of human t-PA/kg body wt in rabbits $2 \mathrm{~h}$ after injection of endotoxin resulted in a decrease of PAinhibitor activity in plasma from $26.3 \pm 6.4$ to $5.5 \pm 1.4 \mathrm{U} / \mathrm{ml}$. This was followed by a progressive increase of PA-inhibitor activity to $28.8 \pm 6.7 \mathrm{U} / \mathrm{ml}(n=2)$ after $60 \mathrm{~min}$ (Fig. 4).

Donor-receiver transfusion experiments were carried out to estimate the turnover rate of PA-inhibitor in rabbits (Fig. 5). Intravenous injection of plasma $(20 \mathrm{ml})$ derived from endotoxin treated animals (inhibitor-rich plasma) resulted in a three- to fivefold increase of the circulating levels of PAinhibitor activity in the receiver animals (from $3.0 \pm 0.5$ to $10.7 \pm 1.9 \mathrm{U} / \mathrm{ml}$ ). This activity decayed with a half-life of about 7 min. No change in PA-inhibitor activity was observed in animals injected with plasma from untreated rabbits, or with plasma from endotoxin treated donor rabbits, which was previously adsorbed with t-PA-Sepharose.

In vitro experiments with $H E C$. Conditioned medium derived from cultured HEC incubated for $12-14 \mathrm{~h}$ in the presence of endotoxin $(10 \mu \mathrm{g} / \mathrm{ml})$ had higher PA-inhibitor activity than that from unstimulated cells (two- to sevenfold increase) (Fig. 6). PA-inhibitor activity was detected also in Triton extracts of endotoxin stimulated HEC $(3.6 \pm 0.9 \mathrm{U} / \mathrm{ml}$, $n=4)$, but was virtually absent in extracts of control cells $(0.2 \pm 0.4 \mathrm{U} / \mathrm{ml}, n=3)$. No PA-inhibitor activity was observed in endotoxin containing culture medium incubated in cell-free wells. Cell fractionation into membrane and soluble fraction revealed that PA-inhibitor activity was confined to the latter fraction. Unstimulated confluent cells derived from different umbilical cords showed a different base-line rate of generation of PA-inhibitor activity, while cells deriving from the same cord generated comparable amounts of inhibitor activity. The endotoxin-induced response (percent increase) was generally more pronounced in HEC exhibiting low levels of inhibitor activity.

Increased accumulation of PA-inhibitor activity in conditioned medium of HEC cultures was already visible $4 \mathrm{~h}$ after stimulation with endotoxin and was detectable at an endotoxin concentration of $0.01 \mu \mathrm{g} / \mathrm{ml} \mathrm{medium} \mathrm{(Fig.} \mathrm{7).}$

A markedly reduced response or no response to endotoxin was observed when confluent cells were stimulated in the absence of human serum. Heat inactivated serum (30 min at $56^{\circ} \mathrm{C}$ ), but not human albumin $(5 \mathrm{mg} / \mathrm{ml})$, supported the endotoxin-induced PA-inhibitor response.

PA-inhibitor activity in plasma of patients with septicemia. As shown in Fig. 8, the plasma PA-inhibitor activity in five 


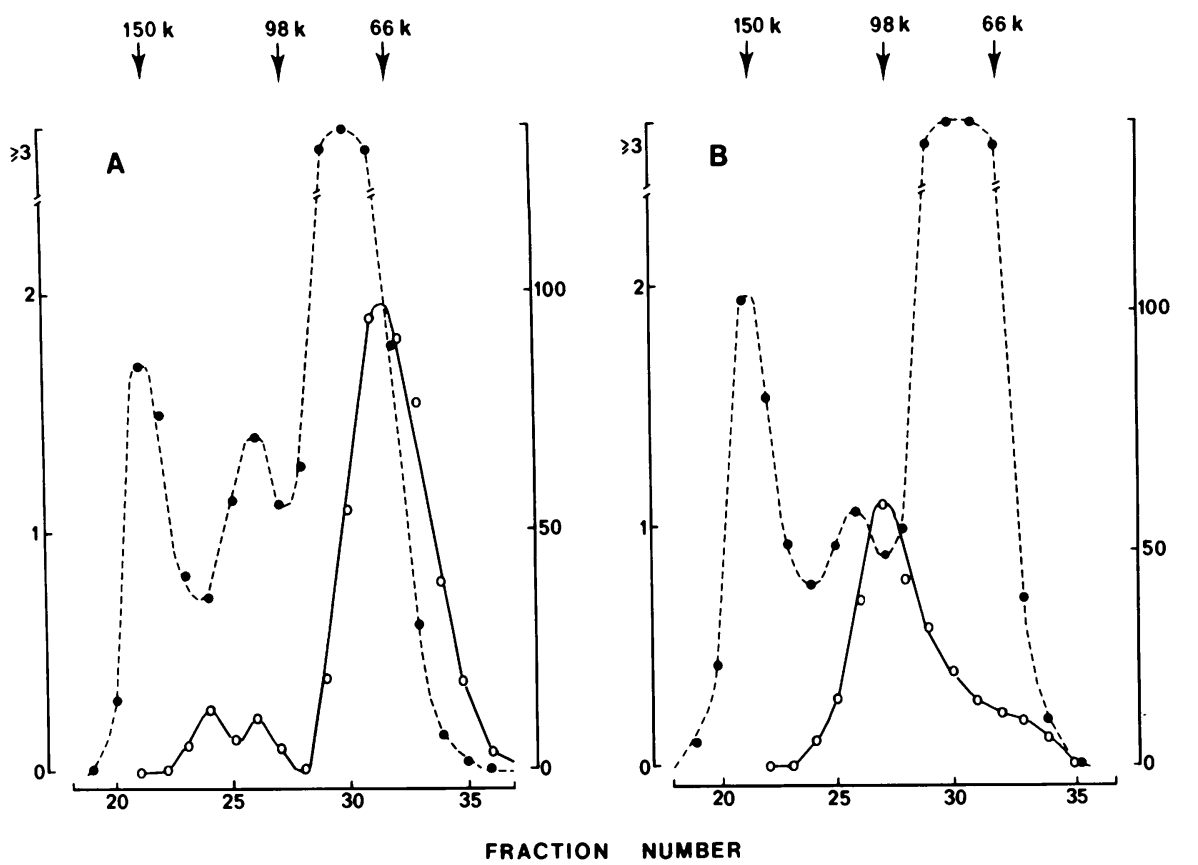

Figure 3. Elution pattern on Ultrogel AcA 44 of plasma samples from untreated rabbits $(A)$ and endotoxin treated rabbits $(B)$ $30 \mathrm{~s}$ after injection of human t-PA $(1,500$ $\mathrm{IU} / \mathrm{kg})$. E. coli LPS $(10 \mu \mathrm{g} / \mathrm{kg})$ or saline was injected $3 \mathrm{~h}$ before injection of t-PA. Blood samples were anticoagulated with trisodium citrate plus D-Ile-Pro-Arg- $\mathrm{CH}_{2} \mathrm{Cl}$ $\left(2 \times 10^{-4} \mathrm{M}\right.$ final concentration). The arrows indicate the elution volume of human IgGs, $M_{\mathrm{r}}=150 \mathrm{k}$; phosphorylase b, $M_{\mathrm{r}}$ $=98 \mathrm{k}$; and human albumin, $M_{\mathrm{r}}=66 \mathrm{k}$. Similar results were obtained in each of three animals. - - - - - - absorbance at $280 \mathrm{~nm} ;-\mathrm{O}-$, t-PA antigen $(\mathrm{ng} / \mathrm{ml})$. patients with septicemia was significantly higher than that observed in a group of 50 control subjects tested simultaneously. Gel filtration analysis of the patient plasma with highest PAinhibitor activity $(41 \mathrm{U} / \mathrm{ml})$ revealed that inhibition of t-PA was associated with a change in the molecular weight, which was similar to that observed in inhibitor rich rabbit plasma. Adsorption of patient plasmas with t-PA-Sepharose resulted in complete disappearance of PA-inhibitor activity.

UK inhibitor activity induced by endotoxin. A very strong correlation ( $r=0.98)$ was found between t-PA inhibitor activity and UK inhibitor activity in patients' plasma, rabbit plasma, and in conditioned culture medium of HEC (not shown). The

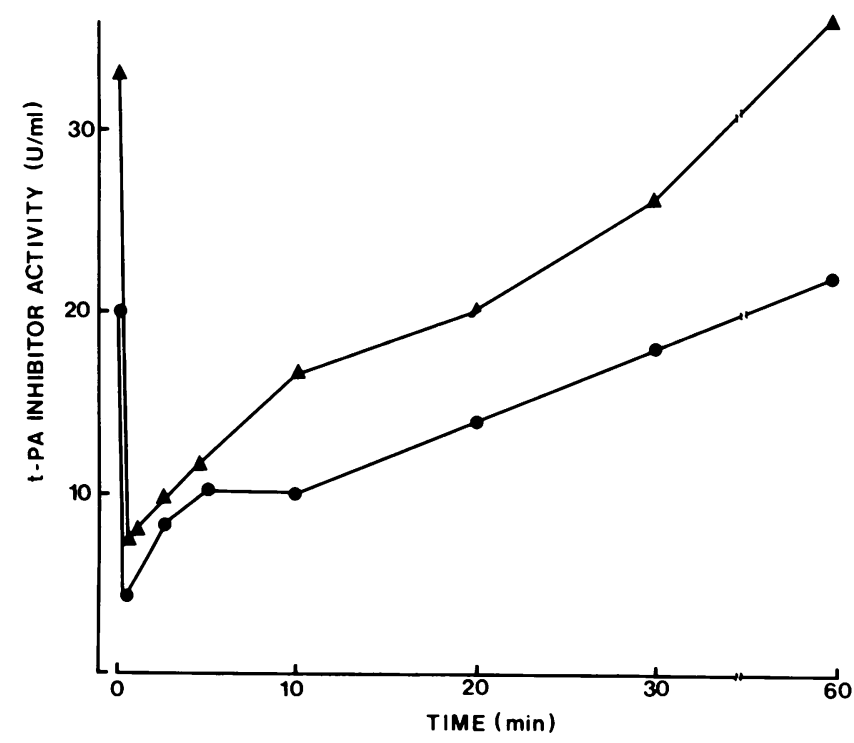

Figure 4. Appearance of PA-inhibitor activity in the plasma of endotoxin treated rabbits. Animals were injected with E. coli $(10 \mu \mathrm{g} / \mathrm{kg}$ body wt) and $2 \mathrm{~h}$ later with human t-PA (1,000 IU/kg body wt). PAinhibitor activity in plasma was then measured at the indicated intervals. Two separate experiments are shown.
UK-inhibiting activity was completely removed by adsorption of the samples with t-PA-Sepharose.

\section{Discussion}

The experiments reported in this paper demonstrate that endotoxemia is associated with a marked and prolonged increase of the circulating levels of PA-inhibitor activity. The dose of endotoxin required for this response is very low $(10 \mathrm{ng} / \mathrm{kg}$ body wt), and far below that which produces overt intravascular coagulation $(200 \mu \mathrm{g} / \mathrm{kg})$.

Inhibition of t-PA in the plasma of endotoxin treated animals is due to the presence of a protease inhibitor as indicated by the following observations. The addition of human t-PA to inhibitor-rich rabbit plasma resulted in a change in the molecular weight of the human activator with the formation of a complex with an apparent molecular weight of 100,000. All the PA-inhibitor activity was removed from plasma after adsorption with t-PA Sepharose. Finally, interaction with the plasma inhibitor was prevented when t-PA was treated with a synthetic active site titrant, indicating that the active site of the enzyme is required for the binding to the inhibitor.

Inhibition of injected human t-PA or of endogenous plasminogen activator(s) by the endotoxin-induced inhibitor also occurred rapidly in vivo. First, no fibrinolytic response to AVP, which is known to induce a marked t-PA release in man (28), was detected in animals preinjected with endotoxin. This might, however, be due to inhibition of plasminogen activator release by endotoxin. Second, no free activator was found in the circulation $30 \mathrm{~s}$ after injection of human t-PA in endotoxin treated animals. The change in the gel filtration pattern of human t-PA antigen paralleled the disappearance of t-PA activity in the blood of rabbits with high levels of PA-inhibitor. In untreated animals, the half-life of human t-PA was, in agreement with previous results (29), $\sim 2 \mathrm{~min}$. It has been demonstrated that clearance of t-PA from the circulation is mainly due to uptake by the liver; no interaction with any of the plasma protease inhibitors could be documented (29). 


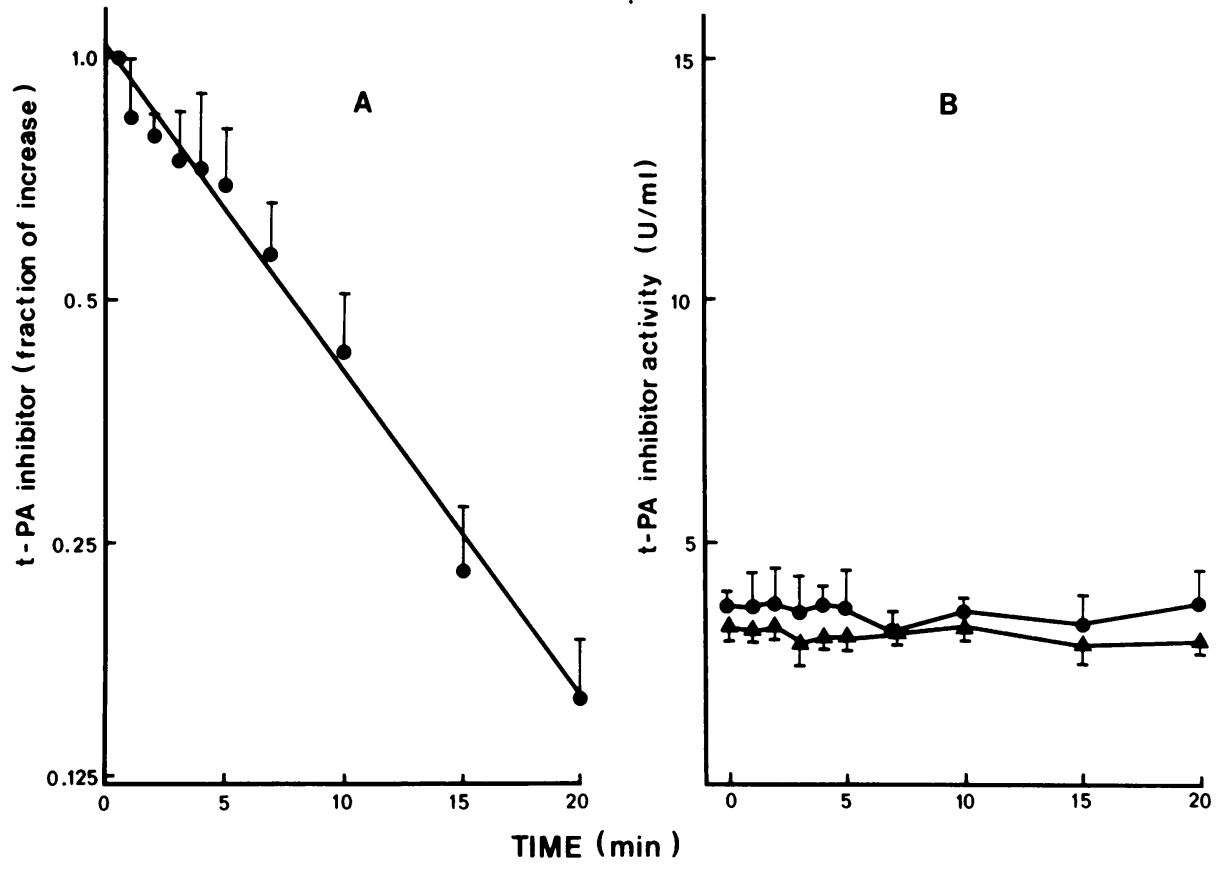

Figure 5. Turnover rate of PA-inhibitor activity in rabbits. $(A)$ Disappearance of circulating PA-inhibitor activity in rabbits injected with inhibitor-rich plasma $(20 \mathrm{ml}, 36-53 \mathrm{U} / \mathrm{ml})$. Results are the mean \pm SD of three experiments. $(B)$ $P A$-inhibitor response in rabbits injected with normal plasma $(\Delta)$ or PAinhibitor rich plasma adsorbed with $t-$ PA-Sepharose (๑). Results are the mean and range of two experiments.
However, in endotoxin treated rabbits, human t-PA activity disappeared within a few seconds, due to neutralization by the circulating inhibitor.

Increased levels of PA-inhibitor activity in endotoxin treated rabbits were maintained for about $5 \mathrm{~h}$. This prolonged response to endotoxin resulted from continuous release of PA-inhibitor into the circulation as indicated by its short half-life (about $\sim 7 \mathrm{~min}$ ) and by the progressive rise in the levels of the inhibitor in plasma after its depletion by injection of human t-PA.

The origin of the PA-inhibitor found in the circulating blood of endotoxin treated animals is unclear. Blood cells do not seem to contribute to this endotoxin-induced response as suggested by the fact that no increase in the cell-associated PA-inhibitor activity was found in leukocytes and platelets isolated from blood obtained from endotoxin injected rabbits. Furthermore, the plasma levels of PA-inhibitor were unchanged

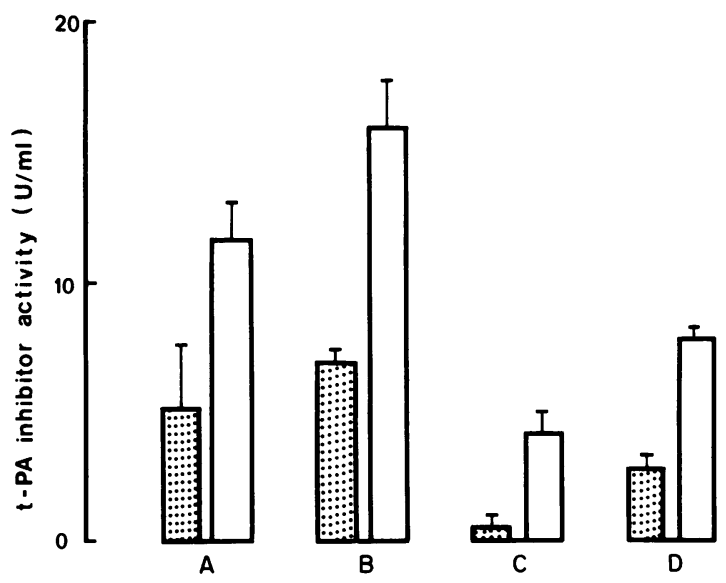

Figure 6. PA-inhibitor activity in the culture medium of HEC incubated for $12-14 \mathrm{~h}$ with $E$. coli $\mathrm{LPS}(10 \mu \mathrm{g} / \mathrm{ml})$ (open bars) or saline (stippled bars). Results represent mean \pm SD of experiments carried out on three separate cell cultures derived from the same umbilical cord. Four series of experiments $(A$ to $D)$ are shown. after in vitro stimulation of rabbit blood with endotoxin. The contribution of the endothelium in the generation of PAinhibitor activity in blood is suggested by the experiments carried out with cultured human endothelial cells. These experiments indeed showed that addition of endotoxin to endothelial cells resulted in an increased accumulation of PAinhibitor activity in the surrounding medium. The available data, however, do not allow us to conclude that the inhibitor found in endothelial cells $(8-12)$ is the same as that found in plasma (13-15).

Stimulation of endothelial cells by endotoxin is mediated by a serum factor that is heat stable and thus does not require activation of the complement system. Cell damage does not seem to be a prerequisite for the occurrence of the endotoxininduced PA-inhibitor response. No endothelial cell damage was observed after exposure to endotoxin in vitro (5). Moreover, the minimum dose of endotoxin capable of inducing a marked inhibitor response in vivo (10 $\mathrm{ng} / \mathrm{kg}$ body wt) is at least two orders of magnitude lower than the dose shown to produce vascular lesions in rabbits $(4,30)$.

All of five patients with septicemia had circulating levels of PA-inhibitor above $4 \mathrm{U} / \mathrm{ml}$, whereas $<1 \%$ of 700 plasma samples from normal subjects had PA-inhibitor activity above this value (unpublished). This suggests that the PA-inhibitor response to endotoxin is a relevant physiopathological phenomenon in man.

The strong correlation found under all conditions between inhibition of t-PA and inhibition of UK, and the fact that all the UK inhibitor activity is removed by adsorption with t-PASepharose, indicate that this fast inhibitor interacts with both plasminogen activators.

The possible role of PA-inhibitor in the pathogenesis of endotoxin-induced DIC is inferred from different observations. First, Hofmann and co-workers (31) showed that infusion of low doses of soluble Des-A fibrin, the product of the proteolytic removal of fibrinopeptide $A$ from fibrinogen by thrombin, resulted in generation of renal glomerular microclots in endotoxin treated rabbits, but not in untreated animals. Microclot 


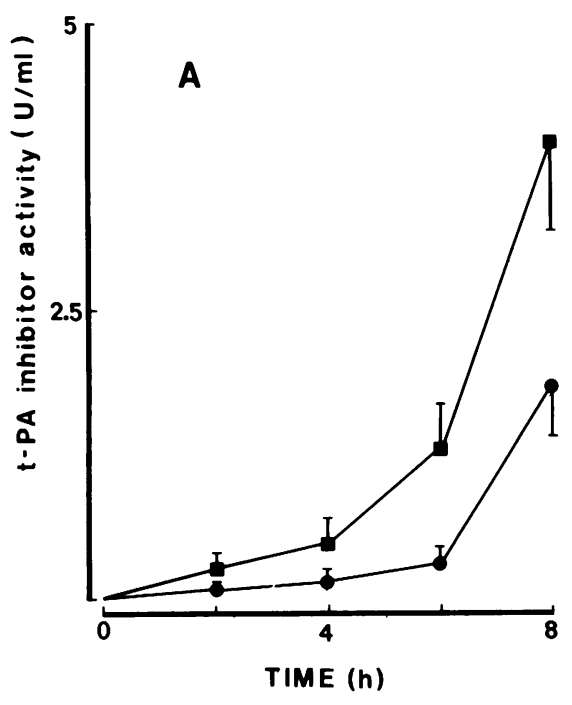

formation seemed to be caused by defective fibrinolysis. Indeed, glomerular microthrombi were also observed after Des-A fibrin infusion in animals treated with aprotinin, a fibrinolytic inhibitor. Secondly, pregnancy is known to predispose to the Sanarelli-Shwartzman reaction (32). Margaretten and colleagues (33) observed that prolonged infusion of thrombin resulted in renal cortical necrosis in a large proportion of pregnant rats, whereas there were no lesions in nonpregnant animals. Thrombin infusion also caused renal cortical necrosis in nonpregnant

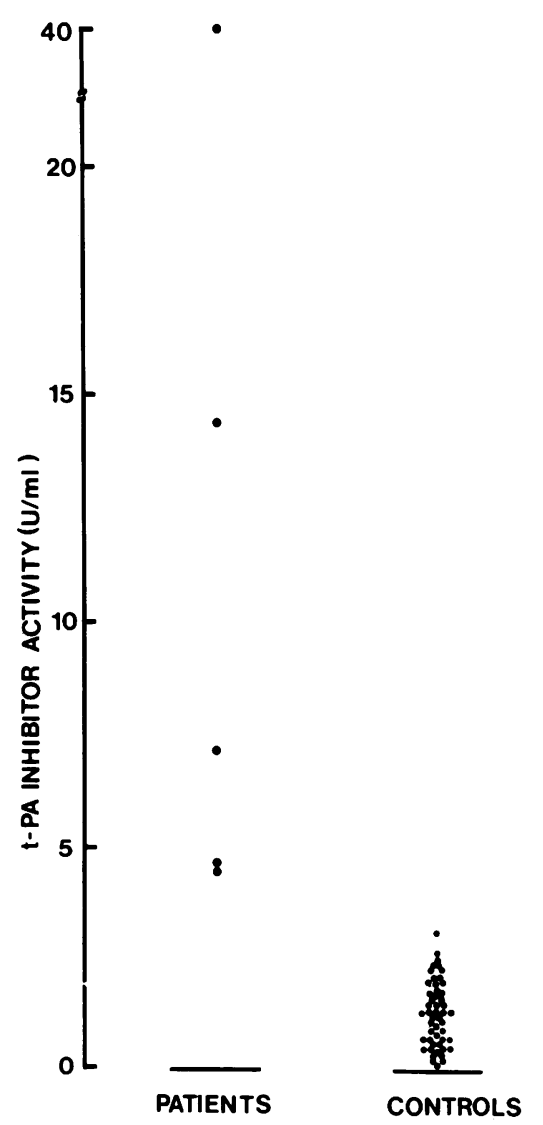

Figure 8. PA-inhibitor activity in plasma from patients with septicemia and normal subjects. animals that had received an infusion of epsilon-amino caproic acid, an inhibitor of plasminogen activation. This again suggests that during pregnancy, the reduction of the fibrinolytic capacity may be one of the pathogenetic mechanisms leading to enhanced sensitivity to thrombogenic stimuli. Finally, recent reports have shown a significant increase of the level of PAinhibitor activity in plasma during pregnancy $(34,35)$.

In conclusion, our results suggest that the generation of a fast-acting PA-inhibitor activity in the circulation may contribute to DIC associated with endotoxemia. The findings that the appearance of PA-inhibitor is very sensitive to certain stimuli and that it efficiently modulates the activity of the fibrinolytic system in vivo underscore its potential pathophysiological role in hemostasis.

\section{Acknowledgment}

This work was supported by the Geconcerteerde Onderzoeksactie (project 80-85/3).

\section{References}

1. Wolff, S. M., and J. V. Bennett. 1974. Gram-negative rod bacteremia. N. Engl. J. Med. 291:733-734.

2. Young, L. S. 1979. Gram-negative sepsis. In Principles and Practice of Infectious Diseases. G. L. Mandel, R. G. Douglas, Jr., and J. E. Bennett, editors. John Wiley \& Sons, Inc., New York. 1:571608.

3. Morrison, D. C., and R. J. Ulevitch. 1978. The effects of bacterial endotoxins on host mediation systems. A review. Am. J. Pathol. 93:526-617.

4. Gaynor, E., C. Bouvier, and T. H. Spaet. 1970. Vascular lesion: possible pathogenetic basis of the generalized Sanarelli-Shwartzman reaction. Science (Wash. DC). 170:986-988.

5. Colucci, M., G. Balconi, R. Lorenzet, A. Pietra, D. Locati, M. B. Donati, and N. Semeraro. 1983. Cultured human endothelial cells generate tissue factor in response to endotoxin. J. Clin. Invest. 71:1893-1896.

6. Nilsson, I. M., U. Hedner, and M. Pandolf. 1980. Physiology of fibrinolysis. In Fibrinolysis. D. L. Kline and K. N. N. Reddy, editors. CRC Press, Inc., Boca Raton, FL. 165-183.

7. Nossel, H. L. 1981. Relative proteolysis of the fibrinogen B $\beta$ chain by thrombin and plasmin as a determinant of thrombosis. Nature (Lond.). 291:165-167. 
8. Dosne, A. M., E. Dupuy, and E. Bodevin. 1978. Production of a fibrinolytic inhibitor by cultured endothelial cells derived from human umbilical vein. Thromb. Res. 12:377-387.

9. Levin, E. G., and D. J. Loskutoff. 1982. Cultured bovine endothelial cells produce both urokinase and tissue-type plasminogen activators. J. Cell Biol. 94:631-636.

10. Emeis, J. J., V. W. M. Van Hinsbergh, J. H. Verheijen, and G. Wijngaards. 1983. Inhibition of tissue-type plasminogen activator by conditioned medium from cultured human and porcine vascular endothelial cells. Biochem. Biophys. Res. Commun. 110:392-398.

11. Loskutoff, D. J., J. A. Van Mourik, L. A. Erickson, and D. Lawrence. 1983. Detection of an unusually stable fibrinolytic inhibitor produced by bovine endothelial cells. Proc. Natl. Acad. Sci. USA. 80: 2956-2960.

12. Levin, E. G. 1983. Latent tissue plasminogen activator produced by human endothelial cells in culture: evidence for an enzyme-inhibitor complex. Proc. Natl. Acad. Sci. USA. 80:6804-6808.

13. Chmielewska, J., M. Ranby, and B. Wiman. 1983. Evidence for a rapid inhibitor to tissue plasminogen activator in plasma. Thromb. Res. 31:427-436.

14. Juhan-Vague, I., B. Moerman, F. De Cock, M. F. Aillaud, and D. Collen. 1984. Plasma levels of a specific inhibitor of tissue-type plasminogen activator (and urokinase) in normal and pathological conditions. Thromb. Res. 33:523-530.

15. Kruithof, E. K. O., C. Tran-Thang, A. Ransijn, and F. Bachmann. 1984. Demonstration of a fast acting inhibitor of plasminogen activators in human plasma. Blood. (in press).

16. Rijken, D. C., and D. Collen. 1981. Purification and characterization of the plasminogen activator secreted by human melanoma cells in culture. J. Biol. Chem. 256:7035-7041.

17. Deutsch, D. G., and E. T. Mertz. 1970. Plasminogen: purification from human plasma by affinity chromatography. Science (Wash. DC). 170:1095-1096.

18. Blombäck, B., and M. Blombäck. 1956. Purification of human and bovine fibrinogen. Ark. Kemi. 10:415-428.

19. Verheijen, J. H., E. Mullaart, G. T. G. Chang, C. Kluft, and G. Wijngaards. 1982. A simple sensitive spectrophotometric assay for extrinsic (tissue-type) plasminogen activator applicable to measurements in plasma. Thromb. Haemostasis. 48:266-269.

20. Fraker, P. J., and J. C. Speck, Jr. 1978. Protein and cell membrane iodinations with a sparingly soluble chloroamide, 1,3,4,6tetrachloro-3a,6a-diphenylglycoluril. Biochem. Biophys. Res. Commun. 80:849-857.
21. Lijnen, H. R., M. Uytterhoeven, and D. Collen. 1984. Inhibition of trypsin-like serine proteinases by tripeptide arginyl and lysyl chloromethylketones. Thromb. Res. 34:431-437.

22. Lagarde, M., P. A. Bryon, M. Guichardant, and M. Dechavanne. 1980. A simple and efficient method for platelet isolation from their plasma. Thromb. Res. 17:581-588.

23. Boyum, A. 1976. Isolation of lymphocytes, granulocytes and macrophages. Scand. J. Immunol. 5(Suppl. 5):9-15.

24. Hoylaerts, M., D. C. Rijken, H. R. Lijnen, and D. Collen. 1982. Kinetics of the activation of plasminogen by human tissue plasminogen activator. Role of fibrin. J. Biol. Chem. 257:2912-2919.

25. Unkeless, J. C., A. Tobia, L. Ossowski, J. P. Quigley, D. B. Rifkin, and E. Reich. 1973. An enzymatic function associated with transformation of fibroblasts by oncogenic viruses. I. Chick embryo fibroblast cultures transformed by avian RNA tumor viruses. J. Exp. Med. 137:85-111.

26. Astrup, T., and S. Müllertz. 1952. Fibrin plate method for estimating fibrinolytic activity. Arch. Biochem. Biophys. 40:346-351.

27. Wiman, B., G. Mellbring, and M. Ranby. 1983. Plasminogen activator release during venous stasis and exercise as determined by a new specific assay. Clin. Chim. Acta 127:279-288.

28. Rijken, D. C., I. Juhan-Vague, F. De Cock, and D. Collen. 1983. Measurement of human tissue-type plasminogen activator by a two-site immunoradiometric assay. J. Lab. Clin. Med. 101:274-284.

29. Korninger, C., J. M. Stassen, and D. Collen. 1981. Turnover of human extrinsic (tissue-type) plasminogen activator in rabbits. Thromb. Haemostasis. 46:658-661.

30. McGrath, J. M., and G. J. Stewart. 1969. The effects of endotoxin on vascular endothelium. J. Exp. Med. 129:833-848.

31. Hofmann, H., I. Mahn, and G. Müller-Berghaus. 1979. The generation of microclots from circulating soluble Des-A fibrin. Thromb. Haemostasis. 42:39a. (Abstr. 80)

32. Wong, T. C. A. 1962. A study on the generalized Shwartzman reaction in pregnant rats induced by bacterial endotoxin. Am. J. Obstet Gynecol. 84:786-797.

33. Margaretten, W., H. O. Zunker, and D. G. McKay. 1964. Production of the generalized Shwartzman reaction in pregnant rats by intravenous infusion of thrombin. Lab. Invest. 13:552-559.

34. Wiman, B., G. Csemicky, L. Marsk, and H. Robbe. 1984. The novel fast tissue plasminogen activator inhibitor in pregnancy. Haemostasis. 14:101a. (Abstr. 183)

35. Astedt, B., L. Holmberg, and I. M. Nilsson. 1984. An inhibitor of t-PA in pregnant plasma. Haemostasis. 14:101a. (Abstr. 184) 